\title{
Moradores de ocupações ilegais urbanas no ensino superior em Recife
}

\author{
Residents of urban illegal occupation in higher education in Recife
}

\author{
Otacilio Antunes SANTANA ${ }^{1}$
}

Abstract

\begin{abstract}
Resumo
Os objetivos deste trabalho foram quantificar e analisar a expansão das ocupaçôes ilegais urbanas e os moradores dessas ocupaçóes egressos do ensino superior, bem como analisar esses reflexos no mercado de trabalho e na aquisiçáo de novas habitaçóes, no período pós-neoliberalismo (2003-2015), no município de Recife. Análise quantitativas e qualitativas foram utilizadas. Os eixos analíticos qualitativos foram: a) potências individuais e coletivas; b) finalidade da educação; c) posições hegemônicas e contra-hegemônicas. Trânsitos de potências (coletiva-individual-coletiva) e de hegemonias (contra-hegemonia-hegemonia) foram registrados a partir da inclusão na educaçáo e com o esteio de políticas federais, fundamentais no processo.

Palavras-chave: Mudanças Sociais. Finalidade da Educação. Hegemonias. Políticas Públicas.
\end{abstract}

The objective of this work was to quantify and to analyze the expansion of urban illegal occupation and the residents of these occupations that graduates of higher education; as well as to analyze these reflexes in the labor market and in new housing acquisition, in post neoliberalism period (2003-2015), in Recife city. Quantitative and qualitative analysis were used. The analytical qualitative axes were: a) individual and collective potencies; b) purpose of education; c) hegemonic and counter-hegemonic positions. Transits in potencies (collective-individual-collective) and hegemonies (counter-hegemony-hegemony) were recorded from education inclusion and with the mainstay of federal policies, fundamental in all process.

Keywords: Social Change. Education Purpose. Hegemonies. Public Policy.

1 Doutor em Ciências Florestais. Professor Adjunto da Universidade Federal de Pernambuco (UFPE), Departamento de Biofísica e Radiobiologia (DBR), Mestrado Profissional em Rede Nacional para Ensino das Ciências Ambientais (PROFCIAMB), Centro de Biociências (CB), Universidade Federal de Pernambuco (UFPE). Grupo de pesquisa CNPq: Educometria. Av. Prof. Moraes Rego, 1235, Cidade Universitária, Recife - PE, CEP: 50670-901. Tel.: (81)21268535. Email: <otacilio.santana@ufpe.br>.

R. Educ. Públ.
Cuiabá

\begin{abstract}
v. 27
\end{abstract}
n. 64

p. $133-156$ jan./abr. 2018 


\section{Introdução}

Viver a pensar na utopia pode ser algo abstrato para quem vive em algum lugar legítimo, porém, para quem não tem um lugar, buscar um se torna sine qua non para se enquadrar em um cenário ecológico, visto o manejo do ambiente e suas relaçóes pessoais e animais (VILLASANTE, 2004). Se primitivo ${ }^{2}$, a exclusão do oikos anula o indivíduo (ODUM; BARRETT, 2011), no concreto institucional, elimina sua identidade e sua subjetividade diante da necessidade de um endereço para qualquer cadastro de pessoa física, na contemporaneidade. Como não é a exceção ou desprivilegio de poucos, indivíduos se unem para ao menos pensar a pantopia (MORE, 1997), na qual, por meio de uma ocupação espacial, buscam a inserção no oikos-nomos e no registro físico. Até os nômades possuem, mesmo que temporário, um espaço para construírem seu oikos e toda relação que dentro e ao entorno emerge.

O aumento da densidade populacional nas cidades e toda complexidade demográfica associada, como processos migratórios, faz suscitar indivíduos marginais ${ }^{3}$ que não possuem residências fixas, resultados do sistema políticoeconômico e de outras variáveis. No Brasil, o déficit habitacional, quantidade de casas que faltam para atender todos aqueles que precisam, atinge 22 milhóes de pessoas (BOULOS, 2015), o que representa, por critérios quantitativos, o número de famílias que não tem casa e, por critérios qualitativos, o número de famílias que mora sem infraestrutura (energia, água, esgoto, coleta de lixo, segurança e transporte público) ou em coabitação (mora de favor). A partir da união desses indivíduos surge o movimento social de ocupaçóes ilegais ${ }^{4}$ urbanas (Movimento dos Trabalhadores Sem-Teto - MTST). Essa coesão é justificada

2 Primitivo no sentido das comunidades pré-históricas (antropologia biológica). Não se tem aqui a intenção de cometer um erro de cum parare coisas diferentes e não de mesma natureza. Atualmente, o sentido de primitivo é utilizado para opor coisas diferentes como se fossem iguais, a privilegiar a cultura dominante sobre a dita cultura primitiva.

3 A margem das instituiçōes e não da sociedade. Todos estão dentro da sociedade. A lembrar que há um processo de criação de uma margem pelo sistema econômico-político vigente, pelo processo da estrutura da dependência: 'para existir o milionário é sine qua non a existência do miserável' (ver SANTOS, 1970).

4 Ilegal no sentido de não possuir uma escritura pública de cessão de posse. As leis são feitas para 'o outro' (aos amigos tudo, aos outros a justiça), por aqueles que têm interesses em uma legalidade que os torne vítimas. Ela não pode substituir a única coisa que torna uma ação legítima eticamente: o entendimento do que ela faz e significa. Esse entendimento leva a liberdade de poder traçar caminhos sem determinação prévia que comprometesse a ética e a vontade de querer fazer isso como o melhor possível naquele momento concreto. Náo há, efetivamente, para as pessoas em condiçấo de Rua, por exemplo, as condiçōes de eticidade para que as leis representem uma alternativa que não seja sua subjugação à escravidão (ver AGAMBEN, 1995). 
pela identificação de sujeitos coletivos em torno de valores, objetivos e projetos em comum, os quais definem os atos e situaçóes sistêmicas antagônicas que devem ser combatidas e transformadas (SCHERER-WARREN, 2006).

Ocupar (Okupar) é viver em um imóvel ou área urbana sem o consentimento de seu proprietário (PRUIJT, 2004). Não só denominaçóes que se caracterizam pela ação podem identificar esse universo. Na Holanda utilizam o termo krakers para designar as pessoas desse movimento social. Em Berlim (Alemanha) se sistematizou o termo instandbesetzen, uma fusão entre instandsetzen (renovar) e besetzen (ocupar). Há denominaçóes de lugares como crash (lugares para usar e sair), na Itália, e squat (Estados Unidos), lugares privados ou públicos ocupados por uma população marginal. Na Europa, as ocupações urbanas, independentes das nomenclaturas, seguem cinco categorias de classificação (MINTZBERG, 1983): a) as ocupações devido à pobreza (população marginal sem habitação); b) ocupaçóes com estratégia de alternativa de vida (movimentos de contra-cultura); c) ocupação empresarial (recupera ambientes abandonados e instaura serviços e produtos relacionados à marca empresarial); d) ocupação conservacionista (de patrimônios históricos, culturais e ambientais para solicitarem a conservação ou não destruição); e) e ocupações políticas (em sedes governamentais, universidades, empresas públicas, etc.; anarquismo).

Neste trabalho se tratou apenas da primeira categoria, porém algumas ocupaçóes urbanas se encaixam em mais de uma categoria (de pobreza, de estratégia de vida, política e conservacionista). No Brasil, também existem vários termos: favelas, invasóes, morros, grotas, baixadas, vilas, ressacas, mocambos, palafitas, entre outros, em que há um consenso em denominá-los comunidades. Tanto na Europa como na América Latina estudos apontaram que nomenclaturas apresentadas, principalmente pela imprensa, tentam reduzir, inferiorizar e estereotipar essas comunidades a oportunistas e desordeiros ${ }^{5}$ (BOULOS, 2015). O Instituto Brasileiro de Geografia e Estatística (IBGE) classificou essas áreas de Aglomerados subnormais no Censo Demográfico de 2010 (IBGE, 2010). Conceitualmente, o IBGE (2010) descreve que é um conjunto constituído de, no mínimo, 51 unidades habitacionais (barracos, casas...) carentes, em sua maioria, de serviços públicos essenciais, ocupando ou tendo ocupado, até período recente, terreno de propriedade alheia (pública ou particular) e estando dispostas, em geral, de forma desordenada e densa. Além desse conceito, dois critérios de identificação foram apresentados pelo IBGE (2010): a) ocupação ilegal da terra, ou seja, construção em terrenos de propriedade alheia (pública ou particular) no momento

5 O autor desse texto é contrário a teses e a denominaçôes depreciativas as Comunidades mencionadas. 
atual ou em período recente (obtenção do título de propriedade do terreno há dez anos ou menos); b) e possuir pelo menos uma das seguintes características: urbanização fora dos padróes vigentes - refletido por vias de circulação estreitas e de alinhamento irregular, lotes de tamanhos e formas desiguais, construçóes não regularizadas por órgãos públicos e precariedade de serviços públicos essenciais. Para sistematização deste trabalho se tomou a conceituação do IBGE, mas não a denominação, na qual se tratará aqui de Ocupaçóes Ilegais Urbanas, ilegal no sentido de não possuir uma escritura pública de cessão de posse.

Os movimentos sociais de ocupaçâao em sua ação coletiva são contrahegemônicos (MESQUITA; NASCIMENTO, 2014), pois enfrentam os modelos políticos e econômicos de acesso à habitação, a especulação imobiliária, a divisão social resultante do processo de estabelecimento habitacional, o patrimonialismo (heranças) de espaços que deveriam ser públicos, a privatização de espaços públicos, a relação do Estado diante das políticas habitacionais versus ocupações empresariais, etc. (BOULOS, 2015). Essa contra-hegemonia no momento da ocupação resulta em um poder relativo (empowerment), pois o Estado deverá dialogar com quem antes não era atendido e propor saídas aos ocupados (PRUIJT, 2004). Saídas essas que são balizadas pelos movimentos por concessóes realizadas pelo Estado a outros movimentos. É contra-hegemônico também pelo cenário que é construído por meio das redes e arranjos com outros grupos, com trocas de experiências, assessorias, consultorias e uniáo no momento do embate com o Poder Público, o que traz ganhos ao movimento, como uma estrutura com assistências geral e mútua, instâncias de razão, associações, assembleias, divisóes do trabalho, criaçóes de pequenas instituiçóes (escolas), campanhas organizadas, comitês, etc. Cria-se, com isso, um ser coletivo, um onto $^{6}$ que dialoga, tensiona e resiste (ABERS; BULOW, 2011).

Quando se estabelecem as ocupações nas coesões intersubjetivas emergem as subjetividades e a tentativa individual do retorno ao sistema nacional de educação (GARCIA, 2004). Dissocia-se aí a suposta dicotomia indivíduosociedade (LACLAU; MOUFFE, 2001) em que o indivíduo, no âmbito da contra-hegemonia (ocupaçôes), busca se inserir em algo hegemônico (sistema educacional). Por que isso? Qual a finalidade da inserção no sistema educacional? Segundo Pruijt (2004), a busca do sistema educacional pelos indivíduos das

6 Onto como um ser coletivo é uma posição teórico-didática e imaginativa. O cuidado aqui é não se confundir com o ser maior positivista, onto como um conceito genérico abstrato ante ao ser real, vivo, corporal, relacional e singular. A intençấo positivista de produzir coisas conceituais, que analogicamente substituíssem, com valor maior e de maior fundamento, as pessoas vivas que são as que fundam, destituem de cada uma, e, portanto, de todas em conjunto, o seu valor político. Em nome da generalidade do cidadão abstrato que não se é ninguém, e se violenta e mata Maria, João, José, Ana... 
ocupações é motivada (potência de agir), (SPINOZA, 2010) pela busca da legitimação pessoal. Se o movimento contra-hegemônico é estigmatizado (ilegal), a educação e sua certificação o traria para a legalidade hegemônica. Outro destaque aqui é que além do sistema educacional (stricto sensu), a construção do conhecimento e a apropriação de um saber (lato sensu) poderia municiar o projeto em comum do movimento e toda sua articulação por eutopias (SARMENTO, 2002). A educaçáo stricto sensu credenciaria o acesso ao mercado de trabalho e à busca de crédito, por vias hegemônicas (desejo de universalizaçáa). Haveria então um discurso de ocupação e fixação na área, com essência e materialidade coletiva (comunidades discursivas), e um interdiscurso em direção a uma elevação da potência do sujeito (MAINGUENEAU, 1991), por exemplo, a busca pelo acesso aos sistemas educacionais. $\mathrm{E}$ ao estar inserido na hegemonia por essa via qual, então, seria o novo discurso em direção à contra-hegemonia? Mirar a utopia não é um pré-requisito da educação? (SARMENTO, 2002).

O embate pós-ocupaçáo é agravado ou atenuado se o Estado possui uma política habitacional acessível (ABERS; BULOW, 2011). Para os sujeitos dos movimentos contra- hegemônicos retornarem a instâncias hegemônicas fica evidente que o Estado deve planejar e executar políticas afirmativas, no caso deste trabalho, para políticas habitacionais, educacionais e de crédito. Por que o Estado? Os sistemas políticos e econômicos possuem uma responsabilidade na construção de indivíduos e populaçóes marginais, o que tende a desembocar nas ocupaçóes ${ }^{7}$ (PAVLOVSKAYA; BIER, 2012). Por isso programas federais, no caso do Brasil, poderiam minimizar as ocupaçôes ilegais urbanas, e quando não, readequá-las ao sistema urbano funcional e eutópico. No período avaliado deste trabalho, pós-neoliberalismo, de 2003 a 2015, políticas habitacionais (Minha Casa, Minha Vida, BRASIL, 2009), políticas educacionais (Reestruturação e Expansão das Universidades Federais Brasileiras REUNI, BRASIL, 2007), políticas sociais (Bolsa Família, Brasil 2003) e políticas de créditos (redução do spread bancário), (DIEESE, 2014) permitiram os primeiros passos para o diálogo em algumas ocupaçóes e finais tópicos, nos quais não se deixou de observar na literatura os conflitos, as resistências, os litígios e os massacres (BOULOS, 2015; GARCIA, 2004).

7 Essa ambivalência se aproxima da figura do Homo sacer no limiar da ordem social e da vida humana. A vontade soberana do Estado (dos interesses da elite dominante) estabelece os limites potenciais da ação do indivíduo ou do coletivo para inclusão e exclusão nesse Estado de Direito. O Homo sacer é aquele que é incluído pela exclusão e excluído de forma inclusiva. É uma vida matável por estar fora do direito. É o que ocorre com os desterritorializados, eles estão expostos à vulnerabilidade da violência por serem desprovidos de qualquer direito, sendo que tal vulnerabilidade se deriva de um ato de direito que os excluíram (ver AGAMBEN, 2003). 
Ao final do período neoliberalista, em 2002, o cenário em Recife apresentava uma taxa de desemprego de 12,6\%. Além disso, 56\% dos jovens em idade escolar estava fora da escola e registrava-se redução da relaçáo entre taxa de emigraçáo e taxa de imigração. A criação das Zonas Especiais de Interesse Social (ZEIS) e o Boom Imobiliário 2000 mais excluíram e acentuaram a divisão social do que incluíram. Ademais, o processo de extinção da classe média e a manutenção do Índice de Desenvolvimento Humano nos Municípios (IDHM) abaixo de 0,5, entre 1991 e 2000, dentre outros motivos, fizeram com que populaçôes marginais (sem vínculo empregatício formal e sem habitaçôes) ocupassem espaços urbanos abandonados e áreas de proteção ambiental (morros, margens fluviais e áreas costeiras, praias e mangues, e outros) (LIMA, 2012).

Então, a hipótese deste trabalho foi que os moradores de ocupações ilegais urbanas (contra-hegemônicos) se inserem no sistema educacional (ensino superior) e, em consequência, se tornam hegemônicos em relação a políticas habitacionais. O objetivo deste trabalho foi quantificar e analisar a expansão das ocupaçóes ilegais urbanas e os moradores dessas ocupaçóes egressos do ensino superior, bem como analisar seus reflexos no mercado de trabalho e na aquisição de novas habitaçôes, no período pós neoliberalismo (2003-2015), no município de Recife-Pernambuco.

\section{Método e Análise}

O método de coleta de dados seguiu duas etapas concomitantes: a quantitativa e a qualitativa. $\mathrm{Na}$ primeira etapa foram elaborados dois mapas: um para 2003 (abril) e outro para 2015 (abril), em que foram delimitadas as áreas classificadas como ocupaçôes (ocupação ilegal urbana) e não ocupaçốes no município de Recife. O método de geoprocessamento foi utilizado mediante arquivos shapes (shp) e manuseado no programa ArcGis (2015), sob imagens de satélite com sensor QuickBird (SANTANA; IMAÑA-ENCINAS, 2011). Os critérios para mapeamento e censo foram os mesmos utilizados pelo IBGE (2011) e comprovadas in situ quaisquer discrepâncias dos dados. Com o mapeamento se pôde estimar a área ocupada $\left(\mathrm{km}^{2}\right)$. As principais áreas ocupadas nominadas e mapeadas, pelas informaçóes obtidas na Secretaria do Desenvolvimento e Planejamento Urbano (PREFEITURA DO RECIFE, 2002), foram avaliadas e outras áreas sem nominaçôes e que se enquadraram nos critérios de classificação das ocupaçóes ilegais urbanas também foram amostradas e analisadas.

Outras variáveis foram levantadas nos dois períodos delimitados (2003 e 2015), para os dois grupos amostrais designados, moradores em áreas de ocupaçóes e não 
ocupaçóes, por amostragem censitária (critérios IBGE, 2000), que foram: a) número de residentes nas áreas delimitadas; b) número de egressos no ensino superior; c) participação em programas federais de auxílio para manutenção e bolsas durante o percurso no ensino superior; d) regime da situaçáo empregatícia no momento da entrevista, se pela Consolidação das Leis do Trabalho - CLT (BRASIL, 1943), se pela Lei 8.112/90 (Regime Único de Servidores Públicos Civis da União, BRASIL, 1990), se autônomo com recolhimento do imposto de renda, se informais (autônomo sem recolhimento do imposto de renda), e se sem trabalho; e) e se adquiriram algum imóvel e qual a forma de obtenção desse imóvel, se à vista, se financiado, se financiado pelo programa federal Minha Casa, Minha Vida, se por outro motivo (herança, doação, etc.), e se ocuparam de forma ilegal outra área ou imóvel. A comparação dos dados e as distinçóes estatísticas significativas entre os anos levantados e os grupos amostrais foram efetuados por meio do cálculo de p a partir do Teste $\chi^{2}$ (ZAR, 2010).

No item c), citado anteriormente, a participação em programas federais de auxílio, manutenção e bolsas durante o percurso no ensino superior foram as bolsas federais originadas de Programas Institucionais de Iniciação Científica (PIBIC), de Extensão (PIBEX), de Iniciação em Desenvolvimento Tecnológico e Inovação (PIBITI), de Docência (PIBID), e outros programas. De igual forma, os auxílios à permanência do aluno, como moradia na casa do estudante, auxílio a refeiçóes no Restaurante Universitário e acesso a cuidados médicos no Hospital Universitário; o Fundo de Financiamento Estudantil (FIES); o Programa Universidade para Todos (PROUNI); e outros auxílios (bolsas de acordos internacionais e contratos temporários de prestação de serviço).

No mesmo período de verificação dos dados quantitativos, anos de 2003 (janeiro a abril) e 2015 (janeiro a abril), as entrevistas do tipo narrativo (SCHÜTZE, 2010) foram realizadas nas ocupaçóes ilegais urbanas com mais de 15 anos de estabelecimento, tempo de estabelecimento de difícil remoção ou desapropriação (FERNANDES, 2011). Três pautas foram apresentadas, uma para indivíduos acima de 18 anos, que foram questionados com a seguinte pauta inicial: Por que você participou da ocupação ilegal urbana? Além disso, duas para os egressos de cursos superiores: Qual a finalidade de sua inserção no sistema educacional, particularmente o de ensino superior, na sua vida pós-ocupaçáo?; e: Você voltaria a participar de açóes de movimentos sociais de ocupação ilegal urbana? As principais démarches ${ }^{8}$ (SANTANA, 2014a; SANTANA, 2014b; SANTANA, 2015; SANTANA et al., 2015; SANTANA, 2016a; SANTANA,

8 No sentido do metamétodo, démarches é a extração de partes de uma narrativa ou de um discurso que contribuem para a construção convergente de uma evidência ou síntese. 
2016b; SANTANA; PETROVA, 2016) da narrativa foram destacadas para discussão e analisadas conforme as adaptaçóes das categorias utilizadas por Mesquita e Nascimento (2014): a) momentos de elevação da potência coletiva e potência individual diante das situaçóes; b) finalidade do sistema educacional para legitimação diante das instituições (relação com o meio instituído); c) trânsito da contra-hegemonia a hegemonia.

\section{Resultados e Discussão}

As áreas de ocupaçôes ilegais urbanas aumentaram em Recife aproximadamente $12 \mathrm{~km}^{2}$, de 2003 a 2015, e o número de moradores nessas áreas aumentou para 127.790 habitantes (Figura 1), todos significativamente $(\mathrm{p}<0,001)$, população que poderia representar uma cidade média na classificação em urbanismo (SILVA, 1946). O ritmo de crescimento dos residentes nas áreas de ocupaçóes $(\approx 2,5 \%$ ao ano) foi maior $(\mathrm{p}<0.001)$ do que nas áreas de não ocupaçôes $(\approx 0,8 \%)$, e o ritmo de dispersão das ocupaçóes teve um acréscimo de $7 \%$ ao ano da área. $\mathrm{O}$ valor médio da taxa de crescimento da população de Recife no período estudado foi de $1,65 \%$, enquanto que a média nacional para as regióes metropolitanas avaliadas no período (2003-2015) foi de 1,36\% (MATION; NADALIN; KRAUSE, 2014) e 1,12\% para cidades da América Latina nos anos iniciais do século XXI: Cidade do México (AGUILAR; WARD; SMITH, 2003), Buenos Aires e La Paz (BOLAY et al., 2005). Esses dados ressaltaram a importância de uma política de inclusão para o meio instituído (política habitacional e educacional) nas cidades, visto as taxas de crescimento da população marginal perante as políticas hegemônicas (ORUETA, 2007). 
Figura 1 - Número de habitantes e área ocupada $(\mathrm{km} 2)$ fora e dentro de ocupações ilegais urbanas em Recife, 2003 e 2015

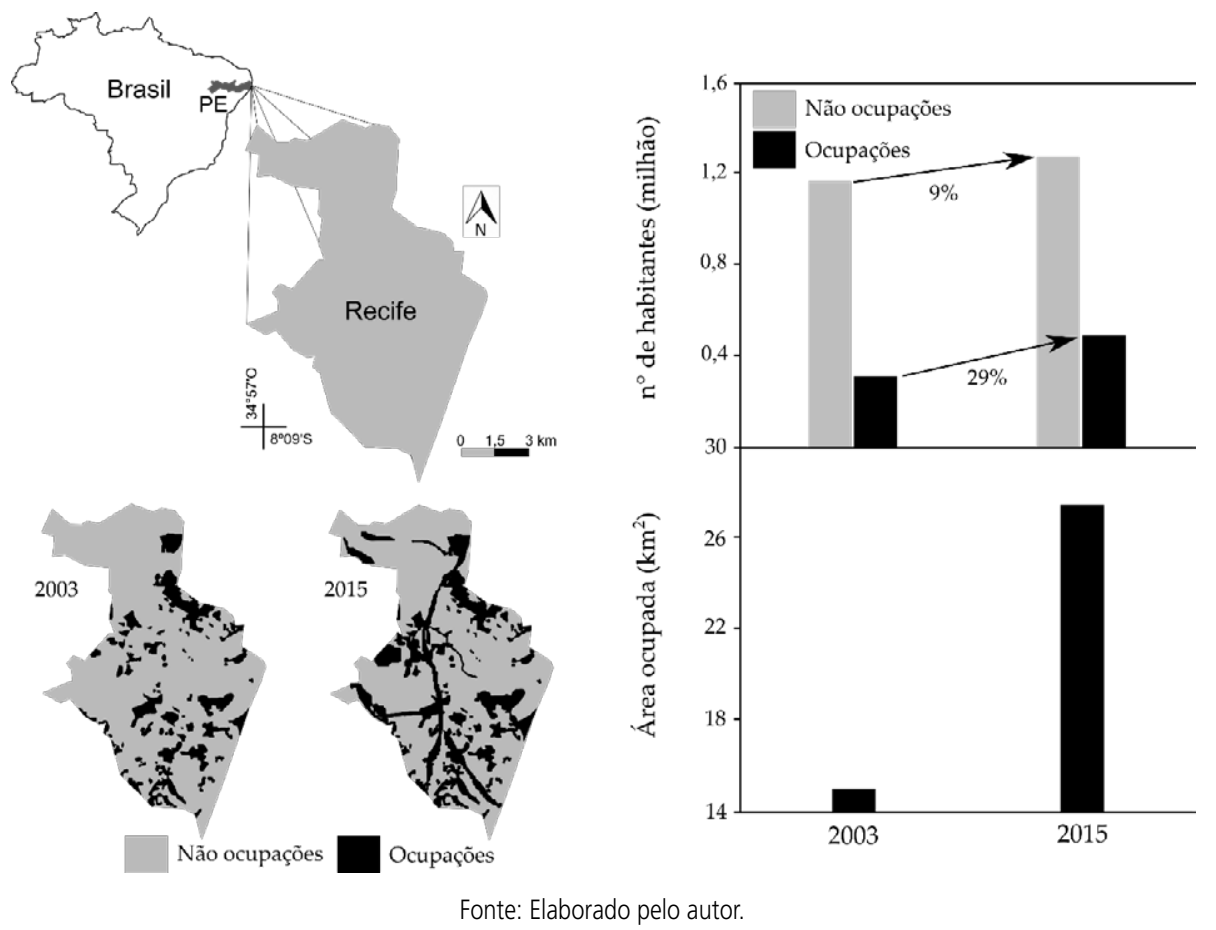

$\mathrm{O}$ número de egressos no ensino superior aumentou significativamente $(\mathrm{p}<$ $0,001)$ de moradores nas áreas não ocupadas $(\approx 67 \%)$ e nas áreas ocupadas $(\approx 90 \%)$ (Figura 2A) no período estudado. Nas duas áreas houve aumento $(\mathrm{p}<0,001)$ de egressos de Instituiçôes de Ensino Superior (IES) públicas em relação a IES privadas (Figura 2B). Em 2003, em áreas não ocupadas, 84\% dos egressos foram de IES privado, e em 2015, foram 43\%. Em áreas ocupadas, em 2003, $97 \%$ se formaram em IES privadas e em 2015, foram 4\%. Esses dados apresentaram o acesso a programas federais de manutenção do aluno na IES (Figura 2C), que aumentou significativamente entre os dois períodos avaliados. Nas áreas não ocupadas, em 2003, 52\% utilizaram algum programa federal, enquanto em 2015 79\% dos egressos utilizaram. Para áreas ocupadas, em 2003, apenas 11\% utilizaram algum programa federal, enquanto, em 2015, 96\% dos egressos utilizaram. Em 2003, majoritariamente, se tinha o FIES como auxílio de manutenção do aluno na IES, enquanto em 2015 se expandiu a diversidade do acesso a auxílios e bolsas (Figura 2B). Os programas institucionais de bolsas e os auxílios sociais conjuntamente foram os recursos mais utilizados em 2015, 75\% para moradores de áreas não ocupadas 
e 85\% para áreas ocupadas (Figura 2D). Não há significância ( $\mathrm{p}>0,05)$ em 2015 entre os grupos amostrais (moradores de áreas não ocupadas e ocupadas) quanto à participação nos programas federais, ou seja, os dois grupos se beneficiaram igualitariamente do programa federal. Todos esses dados corroboram com os dados nacional (GENTILI; OLIVEIRA, 2013), ou seja, no período avaliado, houve uma democratização significativa do ensino superior, observado pelo aumento de vagas para o acesso às IES (77\%), pela ampliação de políticas de manutenção e recursos (11\%) e pelo aumento da relaçáo no número de egresso advindo de IES públicas sobre as IES privadas (11 vezes em Recife).

Figura 2 - A) Número de egressos do ensino superior moradores fora e dentro de ocupações ilegais urbanas; B) Classificação da Instituição de Ensino Superior (IES), se pública ou privada; C) Porcentagem dos egressos que utilizaram programas federais de manutenção; D) Incentivo à permanência universitária utilizado pelos moradores, em Recife, 2003 e 2015
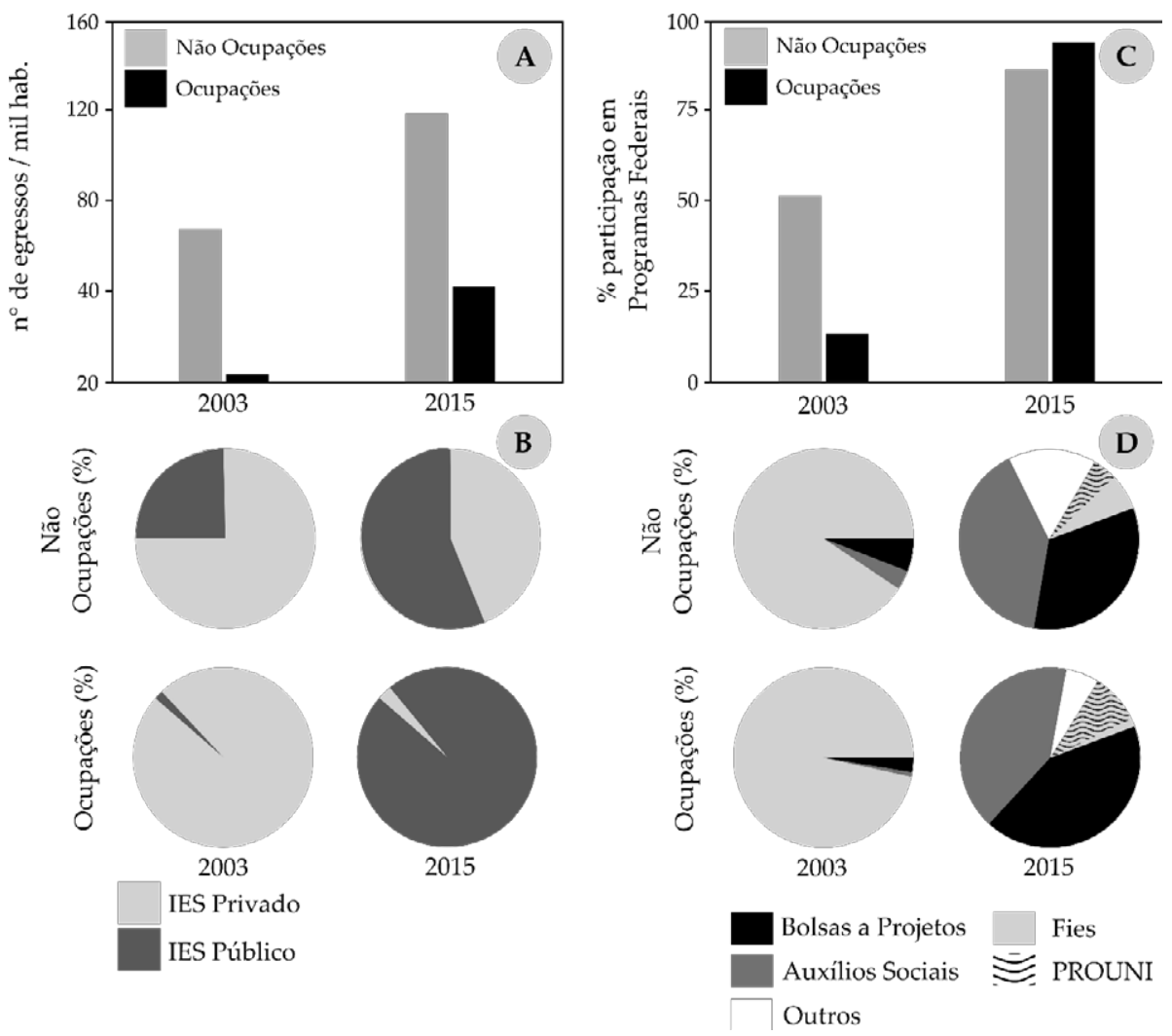

Fonte: Elaborado pelo autor. 
Em relação aos moradores de áreas não ocupadas, em 2003, 54\% trabalhavam registrados (25\% CLT, 13\% Lei 8.112/90 e 16\% autônomos); do restante, $37 \%$ declaravam que não trabalhavam e $9 \%$ trabalhavam informalmente. Em 2015, 89\% trabalhavam registrados (50\% CLT, 22\% Lei 8.112/90 e 17\% autônomos), com $2 \%$ na informalidade e $9 \%$ sem emprego (Figura 3A). Nas áreas ocupadas, em 2003, 13\% dos moradores trabalhavam registrados (8\% CLT e $5 \%$ autônomos); do restante, $16 \%$ declaravam que não trabalhavam e $71 \%$ trabalhavam informalmente. Em 2015, 82\% trabalhavam registrados (36\% CLT, 29\% Lei 8.112/90 e 17\% autônomos), com 8\% na informalidade e $10 \%$ sem emprego (Figura 3A). Ficou elucidado no universo dos egressos anteriormente analisados o aumento da absorção pelo mercado de trabalho sob regimes empregatícios e de comprovação de renda para os dois grupos amostrais, e principalmente da migraçáo da informalidade para formalidade dos residentes de áreas não ocupadas. Os dados corroboram com a literatura (BOULOS, 2015; GARCIA, 2004; MESQUITA; NASCIMENTO, 2014; ORUETA, 2007), que afirmou que a maioria dos participantes de movimentos de ocupação refere-se a pessoas que não vivem na mendicância, e mesmo que na informalidade ${ }^{9}$, estão em atividades laborais.

9 Pessoas que não estấo em atividade laboral regida pela Consolidação das Leis do Trabalho - CLT (BRASIL, 1943), ou pela Lei 8.112/90 (Regime Único servidores públicos civis da Uniáo, BRASIL, 1990), ou pela autonomia com recolhimento do imposto de renda. 
Figura 3 - Número de egressos do ensino superior e seu vínculo empregatício $(A)$ e sua forma de aquisição de imóveis ou áreas (B), em Recife, 2003 e 2015

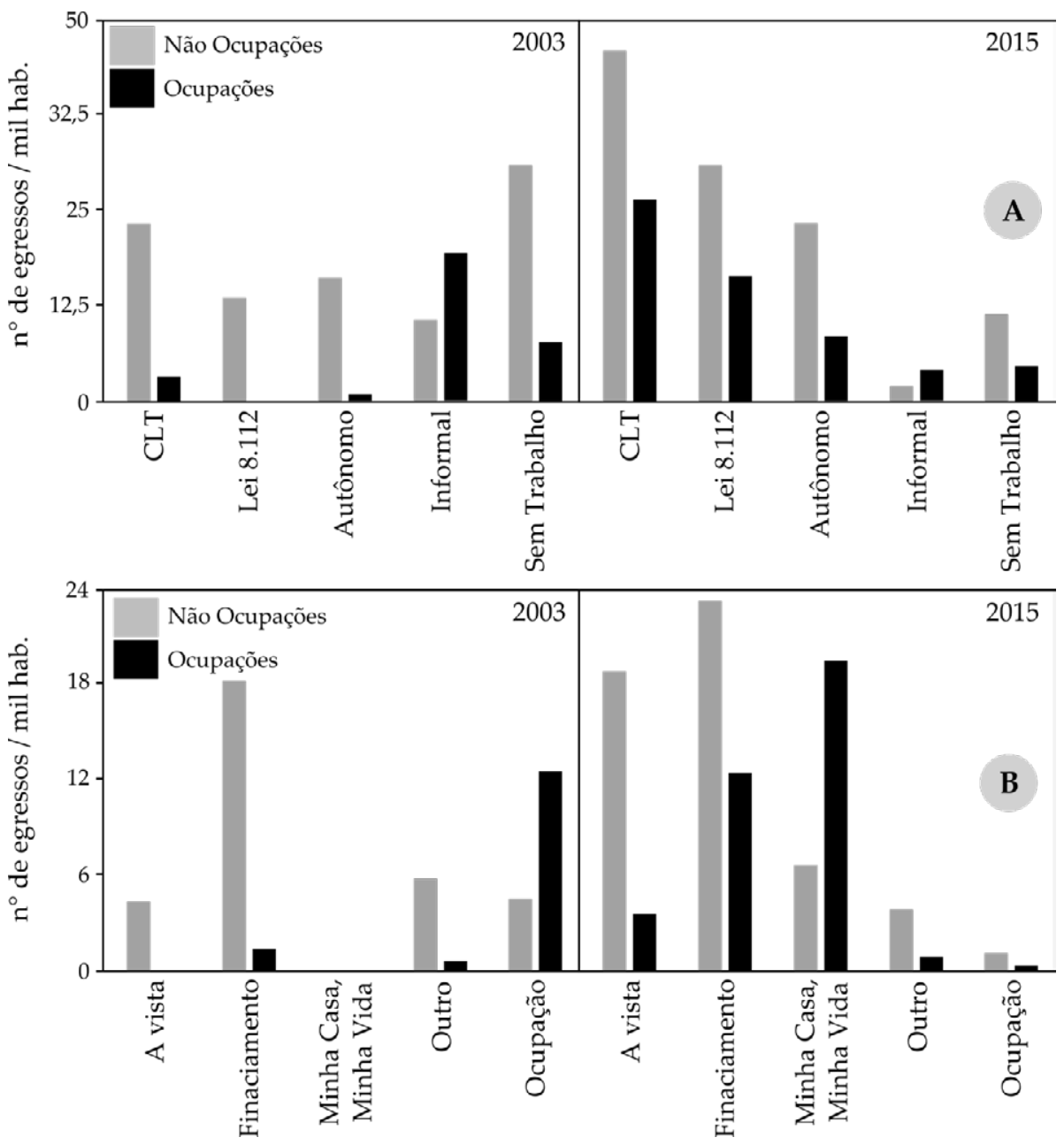

Fonte: Elaborado pelo autor.

Esse aumento da empregabilidade refletiu no consumo, associado a políticas de créditos e programas federais, na aquisição de imóveis pelos egressos do ensino superior, tendência certificada pela literatura, pelo surgimento de uma nova classe trabalhadora (CHAUÍ, 2013) e pela política econômica de consumo (BARBOSA, 2013) vividos nos primeiros dez anos após o neoliberalismo. Em 2003, os moradores de áreas não ocupadas adquiriram seus imóveis basicamente pelo 
financiamento direto a bancos privados e públicos (70\%), e os moradores de áreas não ocupadas basicamente por ocupação ilegal (91\%). Em 2015, os moradores, majoritariamente, adquiriram imóveis por financiamento direto a bancos $(66 \%)$ e à vista (24\%), enquanto os moradores de áreas ocupadas pelo programa federal Minha Casa, Minha Vida registraram 56\%. Menos que 2\% repetiram a participação em ocupaçóes ilegais urbanas dos grupos amostrais avaliados.

$\mathrm{Na}$ análise qualitativa, foram entrevistadas e registradas 1.512 pessoas, para o primeiro questionamento, e 707 pessoas para o segundo e terceiro. Quando se questionou $O$ porquê você da participação na ocupaçáo ilegal urbana todos inicialmente tentavam explanar sobre o motivo de estar sem casa e alegavam que buscavam um lar (utopia). Enquanto se esperava, a resposta sobre o efeito da ocupação em si se dividia em duas causas: a) o recomeço coletivo a partir da marginalização; b) a indignação com a política habitacional. $\mathrm{O}$ desemprego, a promessa do emprego na cidade, a insegurança, o vício, a violência doméstica, o abandono doméstico, a senilidade e o refúgio da seca marcaram as principais causas da marginalização e o ponto de se buscar uma saída para suas situaçôes. Ficou elucidado que a marginalização identificou os indivíduos ao projeto em comum (ter uma habitaçáo), e com isso os mobilizou para a formação de um movimento social de ocupação, corroborado pelas narrativas e pela literatura (MESQUITA; NASCIMENTO, 2014; ORUETA, 2007; PRUIJT, 2004; VILLASANTE, 2004). O turning point (ABBOTT, 1997), segundo as narrativas, não foi a marginalização individual (causa) e sim a junção coletiva no projeto comum (potência coletiva) e na ação (efeito de ocupar). Nesse caso, a contrahegemonia de ocupar nasce e se concretiza por meio da potência coletiva para encarar conflitos e resistir a reaçóes (empowerment), (PRUIJT, 2004).

Perdi meu emprego na qual trabalhava há anos, e como envelheci, não consegui me readequar ao mercado de trabalho. Morava na rua, vivia na insegurança. Ocupar e ter um barraco representa principalmente ter segurança. Me juntar ao movimento me deu segurança e esperança de conquistar algo nessa idade. (Narrativa 1, Ex-cuidadora de idosos, 67 anos, Coque).

Vim de longe trabalhar aqui, com a promessa de fartura, a empresa em que trabalhava faliu e fiquei desempregado. Ocupar para mim é poder reconstruir um espaço para minha família, um ponto de apoio. Juntos se têm mais força para resistir e vigiar a área ocupada. (Narrativa 2, Mecânico, 44 anos, Jordão). 
Eu sou dependente químico e meu ex-marido é alcoólatra e me batia. Ele constituiu outra família e me abandonou. Ocupar representa um recomeço, distante do vício, das agressóes e do abandono. $\mathrm{O}$ vínculo com o movimento me direcionará aos caminhos necessários para a aquisição de meu imóvel. (Narrativa 3, Diarista, 51 anos, Favela do Rato).

Não aguentávamos mais a seca no Sertão, muita fome e não tínhamos perspectiva de futuro. Não adaptamos ao trabalho e aos costumes na cidade. Ocupar poderia ser a última change de 'vingarmos'aqui. Sempre fomos coletivos (no meio rural), lá nos juntávamos para plantar, colher, construir (casas e cercas), festejar, rezar e para nos ajudar. (Narrativa 4, Agricultor, 63 anos, Brasilit 2).

Em outras três démarches (Narrativas de 5 a 7) emergiram outras causas para integração ao projeto ocupar. Marginalizados não pelos motivos anteriormente apresentados, mas pela política habitacional. Os preços acima do poder de compra da maioria da população, o espaço indigno (proximidade e infra-estrutura), a moradia como direito e a injustiça na relação Estado com marginalizados e com as construtoras emergiram nos relatos. Vários relatos transpareceram o sentimento de injustiça, balizado pelo Artigo $6^{\circ}$ da Constituição da República Federativa do Brasil (BRASIL, 1988): "São direitos sociais a educação, a saúde, a alimentação, o trabalho, a moradia, [...]”. Esse artigo, associado ao artigo $170^{\circ}$ : “[...] A ordem econômica, fundada na valorização do trabalho humano e na livre iniciativa, tem por fim assegurar a todos existência digna, conforme os ditames da justiça social, observados os seguintes princípios: [...] III - função social da propriedade [...]" (BRASIL, 1988), são bases legais (depende de interpretação e associação a outras leis) para que os ocupadores justifiquem a posição de injustiçados (falta do poder de compra e indignidade do imóvel), constituam uma potência coletiva ao projeto em comum e revertam as ocupaçóes ilegais em atos legítimos (BOULOS, 2015; SIGAUD, 2004, 2005). Outra injustiça apontada foi a concessão de áreas estratégicas (proximidade a centros comerciais, com entorno ambientalmente preservado, etc.) para as construtoras praticarem especulaçóes imobiliárias (supervalorização do $\mathrm{m}^{2}$ ) e geração de ilhas de nobrezas, regióes em que classes economicamente elevadas conseguem adquirir algum imóvel, o que exclui outras classes econômicas dessas regióes. Em Recife, um exemplo foi o planejamento da construção imobiliária sob o Cais José Estelita (área estratégica), denominado Novo Recife, com uma nítida exclusão social (BARBOSA, 2014). 
Com o meu salário, o que sobra, quando sobra, eu poderia juntar a vida toda, e mesmo assim nunca conseguirei adquirir um imóvel digno. Todo ano o aluguel aumenta acima da inflaçáo, todo ano. Ocupamos para podermos ter nossos imóveis ainda nessa vida e juntos podemos conscientizar outras pessoas que são enganadas sem saber. (Narrativa 5, Pintor, 49 anos, Canal do Arruda).

O lugar onde tenho condiçóes de adquirir uma moradia não tem infraestrutura (energia, água, esgoto, coleta de lixo, segurança e transporte público) e fica muito distante $(>100 \mathrm{~km})$ da área da cidade que me emprega (setores comerciais ou áreas residenciais nobres). Moradia digna é um direito, está na Constituição, se não nos mobilizarmos nunca seremos atendidos conforme a lei. (Narrativa 6, Doméstica, 38 anos, Alto do Refúgio).

Com a especulaçáo imobiliária, as construtoras transformam, em meses, áreas desertas em áreas nobres, com subsídios do Estado, e somos marginalizados. Há um sentimento de injustiça, quando há crises financeiras somos os primeiros a sentir. Ocupamos coletivamente para tentar reduzir as injustiças. (Narrativa 7, Pedreiro, 41 anos, Vila Felicidade).

E qual a finalidade da inserçáo dos residentes das ocupaçóes no sistema educacional $?^{10}$ Duas démarches caracterizaram a maioria das narrativas, uma pela inclusão (Narrativa 8) e a outra pela certificação (Narrativa 9). A inclusão no sistema educacional do marginalizado pela sua posição contra-hegemônica (ocupaçáa) o insere no meio instituído (DELEUZE; GUATARRI, 1997), no caso, a Instituição de Ensino Superior. E quando o meio instituído o reconhece, como ingressante, faz com que o indivíduo saia da condição de apenas uma estatística para um ser com potencialidades (potência individual) (TONET, 2005). Esse ser reconhecido institucionalmente o faz integrador de um ambiente local (cidade), na qual é regido por direitos e deveres (cidadão) (FREIRE, 1996). Estar em um ambiente contrahegemônico, em que é estereotipado socialmente como oportunista ou desordeiro, e a qualquer momento poder ser despejado e, posteriormente, estar em um

10 Há a intencionalidade em algumas análises de se trabalhar na interface de uma descrição funcionalista e de uma descrição analítico interpretativista. Isso em direção a um didatismo, e não para um pré-julgamento normativo e valorativo (codificação). 
ambiente universitário instituído é o trânsito entre situações contra-hegemônicas para hegemônicas, independentemente de onde parte a visão sobre hegemonia (MESQUITA; NASCIMENTO, 2014): ou da sociedade incluída ou dos residentes da ocupação. Nesse ponto a educação cumpre (ou reforça) aos residentes das ocupaçóes suas finalidades: aprendem a conhecer (adquirir instrumentos de da compreensão), aprendem a fazer (para poder agir sobre o meio envolvente), aprendem a viver juntos (cooperação com os outros em todas as atividades humanas) e, finalmente, aprendem a ser (conceito principal que integra todos os anteriores) (DELORS et al., 2010).

Há autores que destacaram a distinção entre educação (lato sensu) e o sistema educacional (stricto sensu) (DELEUZE; GUATARRI, 1997), em que a primeira é um fim e a segunda é um meio para um fim que lhe é exterior (ZABALA, 2002) ${ }^{11}$. No caso da Narrativa 9, e conforme pautado pela pergunta deste trabalho (sistema educacional), a inserção nesse sistema seria a maneira de credenciamento ao mercado de trabalho e a ascensão no poder de consumo. E nesse caso se enquadraria com um meio para um fim exterior, também com potencialidade individual, desapegada dos objetivos contra-hegemônicos do coletivo. E isso é observado nos curriculavitarum dos egressos dessas áreas ocupadas, ou seja, há indicações das atividades e certificaçóes no sistema educacional (hegemônico), mas nenhuma informaçáo sobre um passado de engajamento (modus vivendi) em movimentos sociais de ocupaçáo ilegal urbana (contra-hegemônico), contradiçôes descritas pela literatura na culturalização e transformação pós-moderna (SCOTT, 2010).

A finalidade principal é a inclusão. Frequentar uma aula com alunos de outras classes sociais e discutirmos um mesmo conteúdo é gratificante. Com isso, me senti fortalecido como cidadão. Passei a ter pretensões ainda maiores, a visualizar situaçóes que não estavam no cenário da ocupação. (Narrativa 8, Engenheira, 29 anos, Santa Leopoldina).

O meu diploma me credenciou à busca pelo emprego em um nicho específico, tenho um currículo e oportunidades de ter uma renda maior, e com isso alcançar classes econômicas com poder de consumo maior do que o meu. (Narrativa 9, Advogado, 32 anos, Planeta dos Macacos I).

11 Não existe, na prática, nada que esteja fora que não esteja dentro, e nada que esteja dentro que não esteja fora, as coisas estão juntas, são aspectos de uma tecedura única, com relevâncias e destaques diferenciados, que apresentam em dimensōes casadas. Não há um meio que tenha um fim, nenhum fim que não seja também meio, o que existe é um processo vivo. 
E sobre a pauta se os egressos voltariam a participar de açóes de movimentos de ocupaçáo ilegal urbana, houve unanimidade. Conforme apresentado na Narrativa 10 , todos negaram futuras participaçóes nesses movimentos, e afirmaram que pretenderiam adquirir seus imóveis no universo hegemônico. Esse desejo de se incluir em um agir universalizado e não de exceção (ocupaçóes) faz suscitar um potencial coletivo (desejo ideológico de universalização), mas hegemônico, no qual, segundo Habermas (1981), o fundamento do agir moral flui na possiblidade de universalização das pretensóes normativas subjetivas ${ }^{12}$, observado concretamente na Figura 3 deste trabalho.

Náo, acho que terei a oportunidade de adquirir um imóvel, através do meu acúmulo de recursos ou por créditos que possuo. A conclusão do ensino superior abriu oportunidades que meus pais não tiveram. Batalharei para comprar um imóvel. Ocupar agora seria um retrocesso para mim. (Narrativa 10, Nutricionista, 34 anos, Jardim Monte Verde).

\section{Considerações Finais}

Os programas federais de política de acesso às Instituiçóes de Ensino Superior, de manutenção individual nas IES, de habitação e de crédito foram os esteios para o trânsito de um universo de contra-hegemonia (ocupações ilegais urbanas) a um universo de hegemonia (aquisiçóes de imóveis), no espaço estudado (Recife) e entre os dois períodos analisados (2003 e 2015). Há uma complexidade na aceitação da hipótese, porém os dados quantitativos e qualitativos indicaram que inicialmente há uma potência coletiva gerada pela identificação marginal entre indivíduos, pelo sistema a ser combatido (política pública habitacional) e pela construção de um projeto em comum (movimento social de ocupação ilegal urbana); depois, uma potência individual por ingressar e egressar na IES; e, ao final, um retorno à potência coletiva em um viés hegemônico de universalização de pretensōes subjetivas. Esse trânsito foi sintetizado na Figura 4.

12 Os sujeitos, seja a partir dos princípios marxista, ou a partir de princípios normativos éticos (axiológicos), são voláteis da condição institucional ou 'legal', ou de um estatuto ético como se fosse uma condiçấo universal. O sujeito é um ser peregrinante, en marche, não está concluído, irá mudar em situaçóes novas que se apresentem. Ao fazer isso, ele não é aético, ao contrário, a ética é a criação em uma situação que antes nâo existia, e do caminho possível (ver SARTRE, 1957). 
Figura 4 - Síntese das análises quantitativas e qualitativas

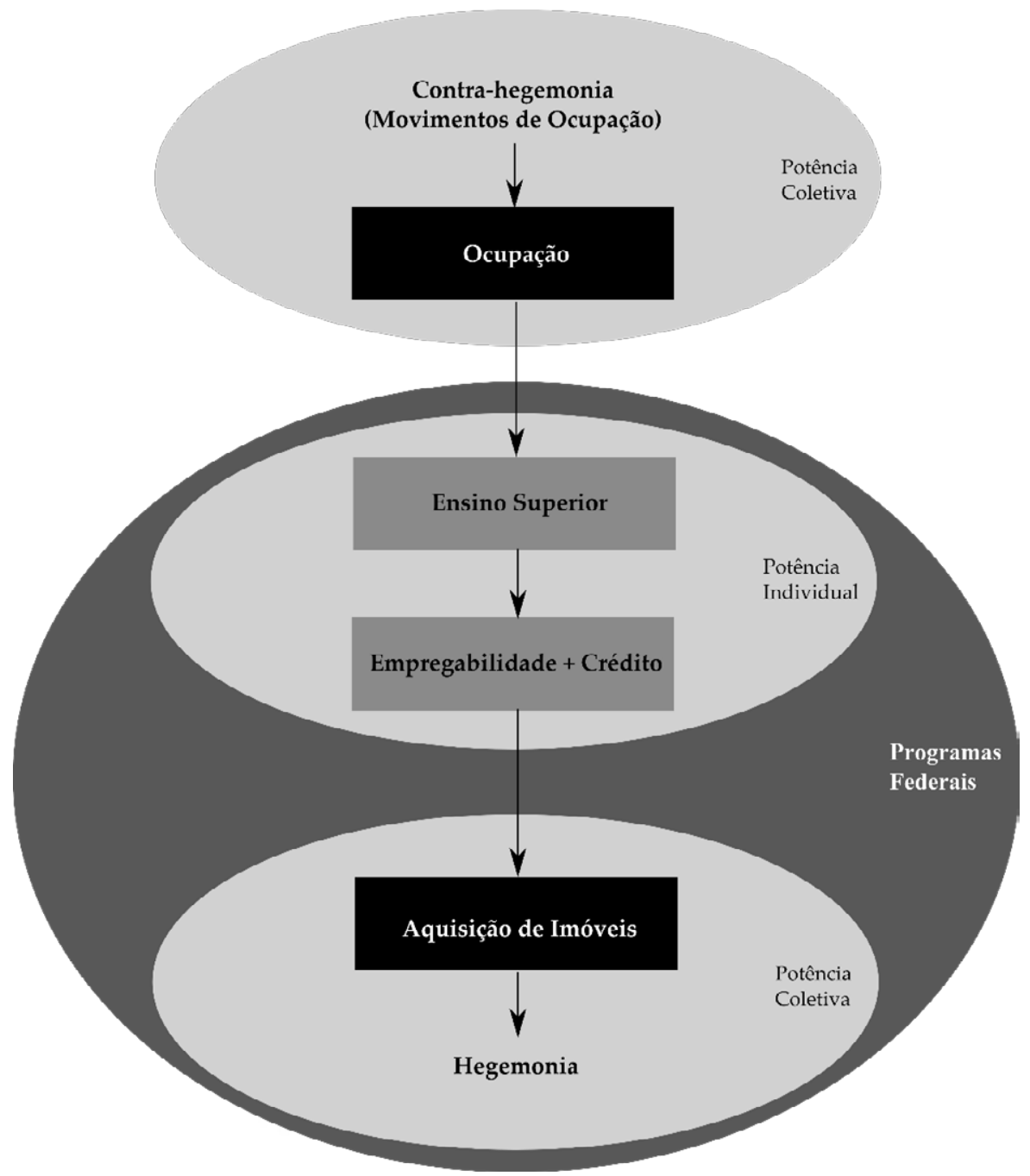

Fonte: Elaborado pelo autor.

A marginalização individual por carência de recursos e a injustiça por falta de acesso a eles foram o estopim para a coesão do movimento de ocupação, segundo relato dos residentes das ocupaçóes. Os dados e a análise permitiram evidenciar que a educação atuou com a finalidade de inclusão cidadã (reconhecimento diante do meio instituído) e o sistema educacional, inserido no universo da 
educação, permitiu um meio (certificação) para a inserção em classes econômicas de consumo e a aquisição de imóvel. A partir daí démarches unânimes sobre o não retorno aos movimentos contra-hegemônicos dos egressos entrevistados marcaram uma transição de marginalizado a incluído em políticas habitacionais.

Há limitaçôes no método, ou seja, Recife não possui limites fechados, há uma mobilidade da população marginal que poderia não representar o universo amostral, a própria amostra perante a representação da população, e outras. Além disso, alguma tentativa pragmatista e reducionista da análise, categorização; porém, os dados quantitativos, qualitativos e a literatura convergiram para um caminho discursivo. Na perspectiva da avaliação de outros espaços e tempos, outras variáveis e análises suscitarão e poderão elucidar erros e acertos metodológicos e analíticos.

\section{Referências}

ABBOTT, A. On the concept of turning point. Comparative Social Research, Bradford, v. 16, p. 85-106, 1997.

ABERS, R.; BULOW, M. U. Movimentos sociais na teoria e na prática: como estudar o ativismo através da fronteira entre estado e sociedade? Sociologias, Porto Alegre, v. 13, n. 28, p. 52-84, 2011. Disponível em: <http://dx.doi.org/10.1590/ S1517-45222011000300004>. Acesso em: 19 nov. 2017.

AGAMBEN, G. Homo sacer. Il potere sovrano e la nuda vita. Torino: Einaudi. 1995. AGAMBEN, G. Stato di Eccezione. Torino: Bollati Boringhieri. 2003.

AGUILAR, A. G.; WARD, P. M.; SMITH, C. B. Globalization, regional development, and mega-city expansion in Latin America: Analyzing Mexico City's peri-urban hinterland. Cities, Beijing, v. 20, n. 1, p. 3-21, 2003. Disponível em: <https://doi.org/10.1016/S0264-2751(02)00092-6>. Acesso em: 19 nov. 2017.

ARCGIS. Mapa, 2015. Disponível em: <http://arcgis.com>. Acesso em: 17 fev. 2015.

BARBOSA, D. T. Novos Recifes, Velhos Negócios: política da paisagem no processo contemporâneo de transformação da Bacia do Pina - Recife/PE, uma análise do projeto Novo Recife. 2014. 245f. Dissertação (Mestrado em Geografia)- Centro de Filosofia e Ciências Humanas, Programa de Pós-graduação em Geografia, Universidade Federal de Pernambuco, Recife, 2014.

BARBOSA, N. Dez anos de política econômica. In: SADER, E. (Org.). 10 anos de governos pós-neoliberais no Brasil: Lula e Dilma. São Paulo: Boitempo Editorial; Rio de Janeiro: FLACSO Brasil, 2013. p. 123-134. v. 1. 
BOLAY, J. C.; et al. Urban environment, spatial fragmentation and social segregation in Latin America: Where does innovation lie? Habitat International, Vancouver, v. 29, n. 4, p. 627-645, 2005. Disponível em: <https://doi. org/10.1016/j.habitatint.2004.05.003>. Acesso em: 19 nov. 2017.

BOULOS, G. De que lado você está? reflexóes sobre a conjuntura política e urbana no Brasil. São Paulo: Boitempo Editorial, 2015.

BRASIL. Aprova a Consolidação das Leis do Trabalho. Decreto-Lei N.o 5.452, de $1^{\circ}$ de maio de 1943. Disponível em: <http://www.planalto.gov.br/>. Acesso em: 23 jun. 2002.

BRASIL. Constituição da República Federativa do Brasil. Brasília, DF: Senado Federal, 1988.

BRASIL. Dispõe sobre o regime jurídico dos servidores públicos civis da União, das autarquias e das fundaçóes públicas federais. Lei No 8.112, de 11 de dezembro de 1990. Disponível em: <http://www.planalto.gov.br/>. Acesso em: 11 jun. 2002.

BRASIL. Bolsa Família, 2003. Disponível em <www.mds.gov.br/bolsafamilia>. Acesso em: 19 jan. 2015.

BRASIL. Reestruturação e Expansão das Universidades Federais Brasileiras - REUNI. 2007. Disponível em: <reuni.mec.gov.br/>. Acesso em: 14 jan. 2015.

BRASIL. Minha Casa, Minha Vida. 2009. Disponível em: <www.caixa.gov.br/ voce/habitacao/minha-casa-minha-vida>. Acesso em: 16 jan. 2015.

CHAUÍ, M. Uma nova classe trabalhadora. In: SADER, E. (Org.). 10 anos de governos pós-neoliberais no Brasil: Lula e Dilma. São Paulo; Rio de Janeiro: Boitempo Editorial; FLACSO Brasil, 2013. p. 123-134. v. 1.

DELEUZE, G; GUATARRI, F. Mil platôs. São Paulo: Editora 34, 1997. 240 p. v. 5

DELORS, J.; et al. Educação: um tesouro a descobrir. Relatório para a UNESCO da Comissão Internacional sobre Educação para o Século XXI. Destaques. Brasília, DF: MEC. 2010.

DEPARTAMENTO INTERSINDICAL DE ESTATÍSTICA E ESTUDOS SOCIOECONÔMICOS (DIEESE). A evolução do crédito na economia brasileira 2008-2013. Nota Técnica, v. 135, p. 2-31, 2014.

FERNANDES, E. Regularização de Assentamentos Informais na América Latina. Cambridge: Lincoln Institute of Land Policy. 2011. 56p. 
FREIRE, P. Pedagogia da autonomia: saberes necessários à prática docente. São Paulo: Paz e Terra, 1996.

GARCIA, R. G. La Okupación y las Políticas Públicas: Negociación, Legalización y Gestión local del Conflicto urbano. In: ARGILÉS, R. A.; LÓPEZ, M. M. (Org.). ¿Dónde están las llaves? El movimento Okupa: Práticas y contextos sociales. Madrid: Catarata, 2004. p. 35-58.

GENTILI, P.; OLIVEIRA, D. A. A procura da igualdade: dez anos de política educacional no Brasil. In: SADER, E. (Org.). 10 anos de governos pósneoliberais no Brasil: Lula e Dilma. Sáo Paulo: Boitempo Editorial; Rio de Janeiro: FLACSO Brasil, 2013. p. 253-263. v. 1.

HABERMAS, J. Theorie des kommunikativen Handelns. Frankfurt am Main: Suhrkamp, 1981.

INSTITUTO BRASILEIRO DE GEOGRAFIA E ESTATÍSTICA (IBGE). 2000. Censo 2000. Disponível em: <http://ibge.gov.br>. Acesso em: 15 dez. 2000.

INSTITUTO BRASILEIRO DE GEOGRAFIA E ESTATÍSTICA (IBGE). Aglomerados Subnormais. 2010. Disponível em: <http://ibge.gov.br>. Acesso em: 9 nov. 2010

INSTITUTO BRASILEIRO DE GEOGRAFIA E ESTATÍSTICA (IBGE). 2011. Censo 2010. Disponível em: <http://ibge.gov.br>. Acesso em: 8 jul. 2011.

LACLAU, E.; MOUFFE, C. Hegemony e socialist strategy: towards a radical democratic politics. 2. ed. Londres: Verso, 2001.

LIMA, R. M. C. de. A Cidade Autoconstruída. Recife: Editora Universitária da UFPE, 2012. 446 p. v. 300.

MAINGUENEAU, D. L'analyse du discours: introduction aux lectures de l'archive. Paris: Hachette Université, 1991. 268 p.

MATION, L. F.; NADALIN, V. G.; KRAUSE, C. Favelização no Brasil entre 2000 e 2010: resultados de uma classificação comparável. IPEA, Brasília, DF, n. 2009, p. 1-44, 2014.

MESQUITA, R. G. de M. de; NASCIMENTO, G. W. do. Brazil's landless rural workers' movement (MST) education and the crisis of the modern science paradigm. Revista Brasileira de Educaçáo, Rio de Janeiro, v. 19, n. 59, p. 1077-1099, dez. 2014. Disponível em: <http://dx.doi.org/10.1590/S141324782014000900013>. Acesso em: 19 nov. 2017. 
MORE, T. Utopia. Brasília, DF: Nova Cultural, 1997. 335 p. (Coleção Os pensadores).

MINTZBERG, H. Structure in Fives: designing Effective Organizations. Englewood Cliffs: Prentice Hall, 1983.

ODUM, E. P.; BARRETT, G. W. Fundamentos de ecologia. São Paulo: Cengage Learning, 2011. 612 p.

ORUETA, F. D. Madrid: Urban regeneration projects and social mobilization. Cities, Beijing, v. 24, n. 3, p. 183-193, 2007. Disponível em: <https://doi. org/10.1016/j.cities.2006.11.004>. Acesso em: 19 nov. 2017.

PAVLOVSKAYA, M.; BIER, J. Mapping census data for difference: Towards the heterogeneous geographies of Arab American communities of the New York metropolitan area. Geoforum, Dublin, v. 43, n. 3, p. 483-496, 2012. Disponível em: <https://doi.org/10.1016/j.geoforum.2011.10.007>. Acesso em: 19 nov. 2017.

PREFEITURA DO RECIFE. Secretaria do Desenvolvimento e Planejamento Urbano. 2002. Disponível em: <http://dados.recife.pe.gov.br/>. Acesso em: 1 jul. 2002.

PRUIJT, H. Okupar en Europa. In: ARGILÉS, R. A.; LÓPEZ, M. M. (Org.). ¿Dónde están las llaves? El movimento Okupa: Práticas y contextos sociales. Madrid: Catarata, 2004. p. 35-58.

SANTANA, O. A.; IMAÑA-ENCINAS, J. Leaf Area Index and Canopy Openness estimation using high spatial resolution image QuickBird. Revista Caatinga, Mossoró, v. 24, p. 59-66, 2011.

SANTANA, O. A. Ensino de ciências em Braille com histórias em quadrinhos roteirizados por cegos. Linhas Críticas, Brasília, DF, v. 20, p. 711-743, $2014 \mathrm{a}$. Disponível em: <https://doi.org/10.5965/15164896v20n432014711>. Acesso em 19 nov. 2017.

SANTANA, O. A. Observaçáo da Prática Docente: um método para Licenciatura. Olinda: Livro Rápido, 2014b. 50 p. Disponível em: <https://doi. org/10.12702/978-85-406-0942-6>. Acesso em: 19 nov. 2017.

SANTANA, O. A. Teachers in Brazil: Social Mobility and Elements for Federalism Strategies. Creative Education, Albuquerque, v. 6, p. 1629-1637, 2015. Disponível em: <https://doi.org/10.4236/ce.2015.615165>. Acesso em: 19 nov. 2017. 
SANTANA, O. A.; SANTOS, N. K. B.; SILVA, M. M. DA; MORAIS, R. L. DE; ENCINAS, J. I. Árvores potenciais a danos urbanos: manejo através da tecnologia, educação e mobilização social. Revista Tecnologia e Sociedade, Curitiba, v. 11, p. 71-88, 2015. Disponível em https: <//doi.org/10.3895/rts. v11n23.2748>. Acesso em: 19 nov. 2017.

SANTANA, O. A. Evasão nas Licenciaturas das Universidades Federais: entre a apetência e a competência. Educação, Santa Maria, v. 41, p. 311-327, 2016a. Disponível em: <https://doi.org/10.5902/1984644415470>. Acesso em: 19 nov. 2017.

SANTANA, O. A. Resistência social na Caatinga árida: a narrativa de quem ficou no colapso ambiental. Desenvolvimento e Meio Ambiente, Curitiba, v. 38, p. 419-438, 2016b. Disponível em https: <//doi.org/10.5380/dma.v38i0.43574>. Acesso em: 19 nov. 2017.

SANTANA, O. A.; PETROVA, Y. Ludicidade no Ensino da Normalidade em um Ambiente Florestal. Inter-açáo, Goiânia, v. 41, p. 525-544, 2016. Disponível em: <https://doi.org/10.5216/ia.v41i3.41502>. Acesso em: 19 nov. 2017.

SANTOS, T. The structure of dependence. The american economic review, v. 60, n. 2, p. 231-236, 1970. Disponível em: <http://www.jstor.org/stable/1815811>. Acesso em: 19 nov. 2017.

SARMENTO, M. J. Infância, exclusão social e educação como utopia realizável. Educaçáo e Sociedade, Campinas, v. 23, n. 78, p. 265-283, 2002. Disponível em: <http://dx.doi.org/10.1590/S0101-73302002000200015>. Acesso em: 19 nov. 2017.

SARTRE, J. P. C. A. L'existentialisme est un humanisme. Paris: Éditions Montaigne. 1957. 70p.

SCHERER-WARREN, I. Das mobilizaçôes às redes de movimentos sociais. Sociedade e Estado, Brasília, DF, v. 21, n. 1, p. 109-130, 2006. Disponível em: <http://dx.doi.org/10.1590/S0102-69922006000100007>. Acesso em: 19 nov. 2017.

SCHÜTZE, F. Pesquisa biográfica e entrevista narrativa. In: WELLER, W.; PFAFF, N. Metodologias da pesquisa qualitativa em educaçáo. Petrópolis: Vozes, 2010.

SCOTT, P. Higher Education and the Transformation of Society. Oxford: Elsevier, 2010. 376p. 
SIGAUD, L. Ocupaçóes de terra, Estado e movimentos sociais no Brasil. Cuadernos de antropología social, Buenos Aires, n. 20, p. 11-23, 2004.

SIGAUD, L. As condições de possibilidade das ocupaçôes de terra. Tempo Social, São Paulo, v. 17, n. 1, p. 256-280, 2005. Disponível em: <http://dx.doi. org/10.1590/S0103-20702005000100011>. Acesso em: 19 nov. 2017.

SILVA, M. M. F. Tentativas de classificação das Cidades Brasileiras. Revista Brasileira de Geografia, Recife, v. 8, n. 3, p. 3-36, 1946.

SPINOZA, B. Ética. 3. ed. São Paulo: Autêntica, 2010. 353 p.

TONET, I. Educação, cidadania e emancipação humana. Ijuí: Unijuí, 2005. 251 p.

VILLASANTE, T. R. Pan-Topias para Okupas. In: ARGILÉS, R. A.; LÓPEZ, M. M. (Org.). ¿¿Dónde están las llaves? El movimento Okupa: práticas y contextos sociales. Madrid: Catarata, 2004. p. 11-20.

ZABALA, A. Enfoque globalizador e pensamento complexo: uma proposta para o currículo escolar. Porto Alegre: Artmed, 2002. 248 p.

ZAR, J. H. Biostatistical analysis. 5th. ed. New Jersey: Prentice Hall. 2010. 944 p. 